\title{
Geografía, método y singularidades revisadas en lo empírico
}

\author{
Everaldo Batista da Costa \\ Universidade de Brasilia \\ Francisco Capuano Scarlato \\ Universidade de Sao Paulo
}

\section{revista}

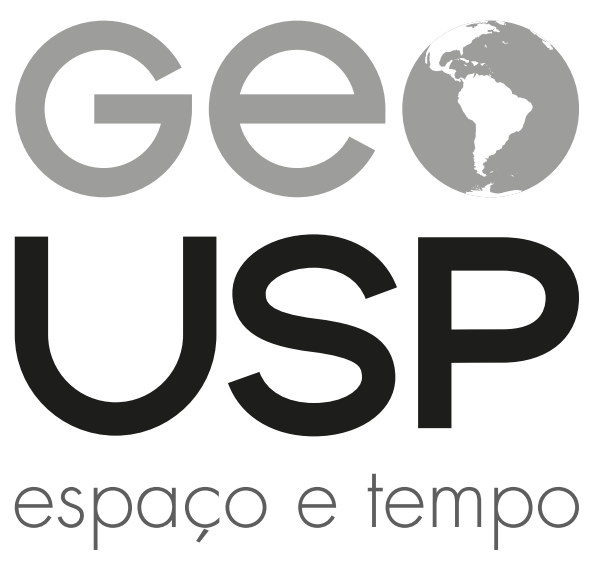

Volume $23 \cdot n^{\circ} 3$ (2019)

ISSN 2179-0892 p. $640-661$

Como citar este artigo:

COSTA, E. B.; SCARLATO, F. C. Geografía, método y singularidades revisadas en lo empírico. Geousp - Espaço e Tempo (Online), v. 23, n. 3, p. 640-661, dez. 2019, ISSN $2179-0892$.

Disponível em: https://www.revistas.usp.br/geousp/article/view/161552. doi: https://doi.org/10.11606/issn.2179-0892.geousp.2019.161552.

\section{(c) $($ i) (8)}

Este artigo está licenciado sob a Creative Commons Attribution 4.0 Licence 


\section{Geografía, método y singularidades revisadas en lo empírico ${ }^{1}$}

\section{Resumen}

Lo que distingue al trabajo de campo en Geografía, en el seno de las ciencias humanas, es que los fenómenos geográficos, en esencia, están dotados de territorialidad o expresión paisajística. Así, el objetivo de este artículo es debatir el estatus científico de los métodos filosóficos y del trabajo de campo en Geografía, en detrimento del activo instrumentalismo, que opaca el sentido categorial de espacio. Metodológicamente, se relacionan (i) el método filosófico como punto de partida de la reflexión disciplinar, (ii) las singularidades geográficas revisadas en lo empírico y (iii) la experiencia didáctica y de investigación de los autores, a través de los trabajos de campo dirigidos en la enseñanza, en la Universidad de Brasilia y en la Universidad de San Paulo, con fundamento en la fenomenología y el materialismo dialéctico. Por medio de las geografías francesa y brasileña y de la experiencia, se valida lo empírico en la comprensión de la interacción sociedad-naturaleza, en el ejercicio de la racionalización crítica del espacio y en la revisión de las teorías y conceptos.

Palabras-clave: Geografía. Método filosófico. Interacción sociedad-naturaleza. Trabajo de campo. Instrumentalismo. Didáctica.

\section{Geografia, método e singularidades revisadas no empírico}

\section{Resumo}

O que distingue o trabalho de campo em Geografia, no seio das ciências humanas, é que os fenômenos geográficos, em essência, estão dotados de territorialidade ou expressão paisagística. Assim, o objetivo deste artigo é debater o status científico dos métodos filosóficos e do trabalho de campo em Geografia, em detrimento do ativo instrumentalismo, que opaca o sentido categorial de espaço. Metodologicamente, são relacionados (i) o método filosófico como ponto de

1 El primer autor agradece al PREI-DGAPA, UNAM, y al Instituto de Geografía de la UNAM, pues parte del artículo fue redactado durante su estancia de investigación en México (2018-2019). 
partida da reflexão disciplinar, (ii) as singularidades geográficas revisadas no empírico e (iii) a experiência didática e de investigação dos autores, através dos trabalhos de campo dirigidos no ensino, na Universidade de Brasília e na Universidade de São Paulo, com fundamento na fenomenologia e no materialismo dialético. Por meio das geografias francesa e brasileira e da experiência, valida-se o empírico na compreensão da interação sociedade-natureza, no exercício da racionalização crítica do espaço e na revisão das teorias e conceitos.

Palavras-chave: Geografia. Método filosófico. Interação sociedade-natureza. Trabalho de campo. Instrumentalismo. Didática.

\title{
Geography, method and singularities reviewed from the empiric
}

\begin{abstract}
Fieldwork in Geography, in the core of human sciences, is distinguished by the fact geographical phenomena are, essentially, characterized by territoriality or landscape expression. This paper aims to debate the scientific status of philosophical methods and fieldwork in Geography, in response to an active instrumentalism, which has darkened the categorical sense of space. Methodologically, there is shown a relationship between: (i) the philosophical method as point of departure for disciplinal reflection, (ii) fieldwork and geographic singularities reviewed from the empiric, and (iii) the authors' didactic and research experience through fieldworks conducted during the teaching process in the University of Brasilia and University of Sao Paulo, grounded on phenomenology and dialectic materialism. Through French and Brazilian geographies along with experience, the paper proves the importance of the empiric in the understanding of society-nature interaction in the exercise of critical rationalization of space and the review of theories and concepts.
\end{abstract}

Keywords: Geography. Philosophical method. Nature-society interaction. Fieldwork. Instrumentalism. Didactic. 


\section{Palabras iniciales: crítica al instrumentalismo en Geografía}

Los discursos sobre instrumentos de análisis en las investigaciones geográficas conducen a la idea de instrumentalismo que, para Blackburn (1997), significa la postura científica de previsibilidad técnica y control de los acontecimientos, sin compromiso con la verdad; para Horkheimer (2015[1947]), es la coerción continua que las modernas condiciones sociales técnicas imponen al mundo, en el núcleo de la razón instrumental. El problema del instrumentalismo está en la coerción práctica y teórica de la realidad traducida por la lógica formal, contabilizada y circunscrita a evidencia tangible de los hechos y fenómenos "positivos".

La contraposición entre el instrumentalismo empírico (comprueba el conocimiento por medio del hecho objetivo, con el mínimo esfuerzo técnico) y el idealismo metafisico (considera la existencia autónoma de las ideas), ${ }^{2}$ que justifica la división de las actividades humanas (trabajo manual material y trabajo intelectual), generó: separación teoría y práctica, alma y cuerpo, pensamiento y objeto, ciencia y filosofía. Esa separación y especialización dieron condiciones al progreso de las ciencias, las cuales establecieron sus métodos de investigación y verificación y se tornaron ciencias positivas (Lefebvre, 1975).

Asumir el compromiso con el método filosófico (o recuperar la Filosofía) exige, en la elaboración de la narrativa teórica en Geografía o en la práctica del trabajo de campo, no reducirlo a la idea de instrumento de análisis, a las dimensiones de la metodología o a los procedimientos. Ese principio del método es medular para quien piensa y opera el espacio geográfico como producto de procesos históricos sociales determinados-determinantes. La Geografía, en búsqueda del conocimiento real del espacio, no queda en el dato inmediato, sino que critica su matematización y ambigüedades. Cuando la manipulación se eleva a método soberano de la filosofía científica, recusando la ontología (Lukács, 2012), se aleja del ser del espacio.

El compromiso con cualquiera de los métodos filosóficos: dialéctico, existencialista, fenomenológico, estructuralista, hermenéutico o con el eclecticismo posmoderno (a veces, difuso y mal explicitado), ${ }^{3}$ incluso el neopositivismo, es incompatible con el instrumentalismo tomado, equivocadamente, como método de análisis geográfico, ello comporta técnicas investigativas. Así, es correcto fundamentar el pensamiento y la práctica de la investigación geográfica en precepto de que el proceso de producción del conocimiento debe ocurrir en relación con el devenir histórico, existencial concreto y representacional del hecho o fenómeno en situación espacial duradera. ${ }^{4}$

Lo que distingue al trabajo de campo en Geografía, en el seno de las ciencias humanas, es que los fenómenos geográficos, en esencia, están dotados de territorialidad o expresión paisajística. Así, este artículo tiene por objetivo debatir el estatus científico de los métodos filosóficos

2 Ver explicación más detallada en Bunge (2013).

3 Moraes (2006) evalua la postura de método individualista, propia de cada investigador, marca personal de fundamentación teórica anclada en el diálogo entre corrientes y autores. Ese individualismo metodológico requiere control y explicación epistémica y de las matrices filosóficas; más que inspiración teórica central u orientación guía. Refuerza el esquivar del discurso del método y las investigaciones son reducidas a técnicas.

4 Ver debate de la situación espacial duradera en Costa (2016). 
y del trabajo de campo en la disciplina, en detrimento de un activo instrumentalismo, que opaca el sentido de espacio geográfico como categoría y objeto disciplinar.

Metodológicamente, se examina (i) el método filosófico como punto de partida de la reflexión disciplinar, (ii) las singularidades geográficas revisadas en lo empírico y (iii) la experiencia didáctica y de investigación de los autores, a través de trabajos de campo dirigidos en la enseñanza, en la Universidad de Brasilia (UnB) y la Universidad de San Paulo (USP), con fundamento metódico fenomenológico y dialéctico, como ejercicio de percepción y de totalización del espacio, desde lo empírico. Dicho análisis estimula la experiencia sensible de los lugares, la relación corporal con el ambiente y las interacciones sociales colocadas en juego en ese contacto, revelando deseos antagónicos expresados in situ (Robic, 2006).

El artículo, basado en las geografías francesa (B. Kayser, P. Claval, Y. Lacoste, J. Tricart, C. Lacoste-Dujardin, H. Théry y M. Robic) y brasileña (A. da Silva, A. Robert Moraes, M. Abreu, A. Damiani, M. Santos, A. Luchiari, F. Scarlato, E. Costa y M. A. Souza), valida lo empírico en la comprensión de la interacción dialéctica sociedad-naturaleza, en el ejercicio de racionalización crítica del espacio y en la revisión de las teorías y conceptos geográficos.

\section{Geografía, método y el punto de partida de la reflexión disciplinar}

Toda definición o conocimiento parte del pensamiento humano (absoluto y universal) y del pensamiento del individuo (relativo y singular). Desconsiderar esas escalas de la conciencia no aproxima el mundo empírico, el pensamiento dinámico y el método, que se acerca de lo real. Los procedimientos analíticos geográficos se modifican en la historia, para el entendimiento del espacio, pues el pensamiento es substancia y práctica, es la consciencia advenida del mundo. Así, en la dialéctica, el pensamiento es acto y poder, debe vincularse con las cosas sobre las cuales actúa; para la fenomenología, ello no es algo, sino conciencia de algo; en ambos métodos, la interacción ocurre entre sujeto y mundo, con el predominio fáctico de uno o de otro. "Toda filosofía es práctica, inclusive aquella que, a la primera vista, parece la más contemplativa. [...] la filosofía debe ser, a una sola vez, totalización del saber, método, idea reguladora [...] el método es una arma social y política" (Sartre, 2002, p. 20).

Pensar la Geografía como ciencia humana crítica de las representaciones espaciales de las contradicciones exige compromiso con los métodos de base filosófica y encuadrar procedimientos e instrumentos analíticos en el ámbito de la hechura táctil de las representaciones que, en sí y de inmediato, no contienen, o no revelan el ser del espacio. Desafíos indispensables en las tesis contemporáneas son el debate, la construcción y la operación del método capaz de impulsar la Geografía hacia la superación de las dicotomías y de las contradicciones espaciales demasiado denunciadas. Huir del abordaje metódico desorienta lo que es la Geografía y a su función en el mundo del presente; admite las más polémicas dicotomías disciplinares: espacio/tiempo, espacio/ sociedad, sociedad/naturaleza, geografía física/geografía humana.

La Geografía es una ciencia humana, pero, en su conjunto, guarda la singularidad de revelar los procesos que fuerzan la interacción dialéctica sociedad-naturaleza, la cual debe interpretarse a la luz de los métodos filosóficos que, de manera y grado diversos y confrontantes, favorecen entender la existencia geográfica subsidiada por el espacio. Incluirla como ciencia adecuada 
a los estudios ambientales, dentro del paradigma crítico, exige comprender su unidad fundada en el espacio geográfico como categoría de totalidad dialéctica, que no pierde de vista las bases de la existencia de la sociedad y del individuo.

Souza (2009) critica el predominio del método analítico en los estudios del medio ambiente y sustentabilidad, en un mundo lleno de contradicciones, donde conceptos son yuxtapuestos para el montaje de un vigoroso discurso político-ideológico. Para esa geógrafa, hay un problema epistemológico en las ciencias humanas y las ciencias ambientales: se confunde historia de la Naturaleza (primera naturaleza) e historia del Mundo (segunda naturaleza), impidiendo la clara lectura del universo discrepante del trabajo. Se debe comprender la relación entre inevitabilidad de procesos naturales y múltiples determinaciones de los procesos sociales. Falta a los geógrafos la lectura epistemológica de las intencionalidades técnicas que rigen la interacción sociedad-naturaleza, reevaluar y neutralizar el peso instrumental de sus investigaciones. Falta asumir el método como la macro teoría o la filosofía capaz de hacer la lectura del real, fundamentando la ontología y la epistemología del espacio, dentro de lo que Lukács (2012) llama mediaciones concretas y auténtica dialéctica de fenómeno y esencia.

Una cuestión teórica y operacional crucial es la superación de la Geografía como ciencia de la relación sociedad-naturaleza. La idea de interacción, más que de relación, aclara, en un mismo conjunto, diferentes partes del todo, de manera que tales partes continúan guardando su existencia y especificidad. Eso corrobora la afirmación de K. Popper, de que toda observación envuelve una interpretación a la luz del conocimiento teórico, y el puro conocimiento observacional, no adulterado por la teoría, si acaso se revelase posible, seria estéril e inútil. La teoría (y el método correspondiente) instiga a romper la constatación inmediata, por su propio progreso y eso depende de la capacidad investigativa del sujeto para revelar el contenido de las interacciones causales y finales de hechos y fenómenos socio-naturales. Existen métodos transdisciplinares que, en rigor, no conocen limitaciones en términos de sus aplicaciones, el caso del positivismo y de la teoría de los sistemas; hay orientaciones que conocen claras restricciones en su aplicabilidad, como el materialismo y la fenomenología (Moraes, 2014).

La interacción geográfica es la acción simultánea entre dos o más fenómenos o hechos espaciales, acarreando mudanzas en las partes y el todo, lo que ofrece como resultado una totalidad dialéctica de co-realizaciones. Un ejemplo son las catástrofes políticas (dichas naturales) en las laderas de valles de climas tropicales, como resultado de la interacción entre (i) formas de asentamiento urbano, planeamiento y gestión territorial y (ii) suelo producido naturalmente. El desafío y la fuerza del método en Geografía están en la captura del movimiento del espacio, posible a través de uno o algunos de los infinitos flashes o momentos de interacción sociedad-naturaleza, cuya constitución es definida por la indisociabilidad de variables generadoras de las contradicciones inherentes, como la intencionalidad, la política y la técnica promotoras de una voluntad absurda de espacio.

El método en Geografía debe buscar, sobre la producción y la percepción del mundo en su totalización, los fenómenos de lo real. La totalidad no es una categoría absoluta, sino, dinámica y relativa. La parte encuentra su razón de ser en las interacciones mutuas que genera. En Geografía, la multiplicidad de interacciones humanas socializan la naturaleza y producen los paisajes como momento visible y singularidad del espacio, lo que nos permite pensarlo como una 
totalidad. Es difícil aceptar la Geografía que aboga por un espacio dual, fragmentado entre físico y humano, separado del tiempo, absolutizado en la materia, apartado de la sociedad. La interacción compleja sociedad-naturaleza es lo que posibilita pensar la unidad disciplinar y demanda revelar las contradicciones entre sus momentos y la totalidad, la cual tiene en el espacio (y sus representaciones en el paisaje y el territorio) expresión y síntesis de la socialización técnica de la naturaleza y de una sociedad técnicamente dominada.

Pensar y operar la naturaleza en sí es abstraer la realidad geográfica de la política y de la técnica, es banalizar el territorio y el paisaje como conceptos y hechos. La concreticidad de la naturaleza está en el infinito de interacciones dadas por el trabajo social cuya motricidad adviene de la dialéctica de la historia vinculada con la conciencia, la percepción y la existencia espaciales. La concepción dual del espacio en Geografía es el error metódico con su escisión de la dialéctica del propio espacio. K. Kosík dice que el individuo transforma la realidad de la naturaleza natural y de la naturaleza suya; él se origina de la naturaleza, es parte de ella y al mismo tempo la ultrapasa. Para el autor, por la praxis humana se opera la metamorfosis objetivo $\leftrightarrow$ subjetivo, ella se transforma en el centro activo donde se realizan las intenciones y se revelan las leyes de la naturaleza, fundiendo causalidad y finalidad, donde la conciencia registra y proyecta, verifica y planifica. La interacción dialéctica sociedad-naturaleza es el catalizador del devenir geográfico existencial, transtemporal y transescalar de los hechos y de los fenómenos localizados (generada por y generadora del mundo del trabajo y de la conciencia individual y colectivo sobre el espacio).

La teoría de Kosík aplicada a la Geografía muestra la totalidad como la multiplicidad de determinaciones generadas en la interacción sociedad-naturaleza, que ninguna otra ciencia humana incorpora. El trabajo (y la conciencia del mundo) revelan procedimiento, acción e imaginación constituyentes de la unidad socio-natural, en recíproca transformación: objetivación social por el trabajo y objetificación de lo natural.

Así, el punto de partida de la reflexión disciplinar geográfica está en las múltiples formas de interacción dialéctica sociedad-naturaleza, determinadas por el mundo y la conciencia política del mundo; no está en el instrumentalismo técnico. La singularidad de la Geografía es de una ciencia humana que se expresa en el espacio signo, significante y significado de infinitas y múltiples interacciones sociedad-naturaleza. Para Milton Santos, es una ciencia del espacio total, indivisible. Un espacio donde cada uno de sus puntos es solidario con los demás, en todo momento (idea de totalidad del espacio); solidaridad resultante de esas interacciones.

Puesto que para las otras ciencias de la sociedad el espacio es una externalidad de su objeto, localización referencial, palco geométrico de acciones, aquellas desprestigian las interacciones entre los fenómenos espaciales y la naturaleza socializada, para la Geografía, la localización, la situación, la posición, la extensión y la existencia en y del espacio son comprendidas por esas interacciones cuya esencia es el control técnico y político. Estamos de acuerdo en que las técnicas adoptadas en la Geografía deben estar al servicio de la política de prevención, de denuncia y de represión a las diferentes formas espaciales de violencia, como mostraron Théry et al. (2011) en relación al trabajo esclavo en Brasil. Además, los instrumentos técnicos o las técnicas de investigación deben ser adoptadas desde una postura ética y existencial del investigador en campo (Matthey, 2005), pero no son sinónimos de método, fuente de la verdad, ni explican dicho control. 
Para la Geografía, la esencia del espacio es interaccional, de correspondencia técnica, de base política y de fundamento existencial. Significa decir que sus singularidades son revistas, también, en lo empírico, asumiendo que tanto la dialéctica como la existencia deben ser procuradas en la interacción sociedad-naturaleza y sujetos entre sí, como enseña J. P. Sartre.

\section{Singularidades geográficas revisadas en lo empírico: estatus científico del trabajo de campo}

Evaluaremos el significado del trabajo de campo o su estatus científico para los geógrafos. Las construcciones teóricas disciplinares podrán estar en la entrada o la salida de las investigaciones de campo. Al inicio de la práctica, después de delinear el tema y la localización, se hace la observación, para inventariar posibles interacciones de hechos y fenómenos. No debemos ir a campo sin antes estudiar las fuentes teórico-filosóficas de la investigación. El trabajo de campo no debe ser asumido como tabla rasa. Para el fenomenólogo, la evidencia es conscientizada o internalizada, para el dialéctico, producida o externalizada; ambas perspectivas son considerables. Los clásicos afirmaban que la Geografía es una ciencia de observación (antes, de la Tierra, hoy, del Mundo), búsqueda de las evidencias y de la multiplicidad de interacciones invocadas por el tema. Es crucial meditar el tipo de empiría a practicarse en Geografía, que es una subtotalidad, una ideología de lo cotidiano expresado en la aprehensión de la espacialidad de valor relacional contenido en lo real, como afirma A. Correa da Silva.

Para K. Popper, las preguntas del empirista - ¿Como sabe? ¿Cuál es la fuente de su afirmación? - están mal formuladas y equivocadas; son preguntas que piden respuesta autoritaria. No hay fuentes ideales; todas ellas nos pueden inducir al error. Para Popper, la pregunta de las fuentes de conocimiento puede sustituirse por: ¿Cómo podemos tener esperanza de identificar y eliminar el error? La respuesta sería: Criticando las teorías o conjeturas de otros - y si somos capaces - criticando nuestras propias teorías o conjeturas. Al movimiento de revisión teórica por medio de lo empírico, Popper lo llama racionalismo crítico.

Racionalizar el espacio geográfico, críticamente, es práctica singular de la disciplina, posible por el trabajo de campo, el análisis del paisaje producido o del territorio configurado, para redefinirlos como conceptos, según se presenta la realidad a la luz de los métodos. El movimiento concreto de esa racionalización es: texto elaborado para el campo $\leftrightarrow$ empírico $\leftrightarrow$ revisión del texto previo $\leftrightarrow$ propuesta de pequeña teoría $\leftrightarrow$ acercamiento de la realidad espacial anhelada. Ese cuidado puede polemizarse con K. Popper (2010[1960], p. 136), quien señala que "en los pretendidos problemas filosóficos, los positivistas ven pseudo problemas [...]. Para el positivista, la experiencia es un programa, no un problema". El estudioso que asume la misión social de la Geografía adopta lo empírico como experiencia espacial inherente al problema de investigación y fuente de teoría. En el campo, el geógrafo evidencia su capacidad intelectual y subjetiva (la intuición, la sensibilidad, el gusto, la estética, la diferenciación cualitativa del mundo), comenta Claval (2013).

La trampa que puede capturar al geógrafo en campo está en la atracción más cartesiana y menos relativa del espacio. Recordemos que el espacio definido es el geográfico, medio y fin, núcleo duro de la investigación disciplinar de la multiplicidad de interacciones sociedad-naturaleza productoras de acciones y objetos que califican los lugares. El espacio geográfico dinámico 
es producto y productor de eventos históricos, de memorias e identidades inherentes a lugares, hechos y fenómenos situados e interactuantes. Camille Lacoste-Dujardin señala que, en la investigación a profundidad, no está en juego solo el estudio en sí, sino las consecuencias de las intervenciones prácticas y/o teóricas, pues las informaciones (memorias e identidades del lugar restrictas a ciertos niveles sociales) son colocadas en circulación en el conjunto del grupo estudiado y fuera de él. La transescalaridad y la transtemporalidad deben conducir la comprensión de las conexiones espaciales en el trabajo de campo, para revisar no solamente el método, la teoría y conceptos, sino las singularidades geográficas conectadas con la realidad.

A. Luchiari es un ejemplo de investigador brasileño que, para superar las dicotomías tocantes a la disciplina - especialmente a la geografía físicallgeografía humana -, desenvolvió serios estudios interaccionales de la sociedad-naturaleza y del espacio-sociedad, caso de su tesis de libre docencia, Tratamento da informação geográfica: estudo sobre distribuição espacial de categorias socioprofissionais; considera la inserción de las mujeres en el mercado de trabajo paulistano y la activación del circuito superior de la economía urbana, a partir de trabajos de campo para definición funcional y morfológica de barrios de San Paulo, de datos oficiales, de representaciones del espacio y de la teoría crítica geográfica. Luchiari atiende lo que Archela e Théry (2008) defienden: la búsqueda de métodos que abarquen la representación de los procesos complejos de la contemporaneidad, lo que provoca el aumento de investigaciones en áreas emergentes como salud pública y medio ambiente.

El trabajo de campo en Geografía, en el proceso de producción del conocimiento, no puede reducirse a una visión simplista de las técnicas. Cuando M. Santos dice que la Geografía es una filosofía de las técnicas, es para permitirnos pensar la disciplina y la técnica no como un hacer mecánico, sino para totalizar las acciones, los procesos productivos y la materialidad derivada impregnada de intencionalidades; obliga a pensar el campo teóricamente y a practicarlo mas allá del empirismo. Y. Lacoste y M. Robic señalan necesario saber pensar el espacio, no restringiendo los problemas al cuadro local; hay que articularlos, encontrar lo desconocido, descubrir ambientes, establecer contactos con informantes y redes mercantiles (aprovechando la eficacia de las técnicas y cuestionándolas).

Con ese paradigma miltoniano que involucra Geografía, Filosofía y Técnica, el campo no puede marcarse por la visión de un conocimiento empirista. Ir a la práctica de campo como quien espera descubrir lo nuevo coloca la Geografía como área del conocimiento desprovista de teorías (M. Heidegger considera toda ciencia enraizada en la Filosofía, con la esquizofrenia de su carácter utilitario, alejado de la vida, centrado en la técnica y al resultado). Para B. Kayser (2006), solo el estudio de la inserción del sub-sistema local (percibido) en el meta-sistema (teorizado) da sentido a la investigación de campo, donde se descubre, en la complejidad y globalidad, la realidad de un sub-sistema social localizado.

El trabajo de campo y la observación son oportunidades de legitimación de las teorías y hallazgos de nuevos fenómenos no contemplados por las mismas, para, entonces, revisar la base teórica. Pero, el hallar nuevos fenómenos, para los cuales las teorías llevan al campo, nunca fuerza la plena negación teórica, al contrario, demanda elaboración de nuevas teorías, con base en lo real empírico, en la realidad concreta y en la teoría anteriormente probada y confirmada. La 
teoría y la singularidad geográficas se revisan en lo empírico, a la luz de las interacciones sociedad-naturaleza definidoras (empíricas y abstractas) de paisaje, territorio, lugar y región (subconceptos de la categoría espacio geográfico). Lo empírico conlleva los fundamentos y las crisis de los fundamentos geográficos; crisis de la estructura interna de la Geografía, de su esencia, donde sus conceptos fundamentales se tornan vacilantes con el cambio del mundo. ${ }^{5}$

Todas las teorías en Geografía se sustentan, singularmente, por fenómenos territorializados y producidos como paisaje. "Lo geográfico está delante de nuestra percepción, aquello que se ve, un momento de la existencia de una configuración del espacio por el movimiento diferenciado y múltiple" (Silva, 2000, p. 13). Tan importante como llevar a campo instrumentos y equipos es desarrollar el mirar, el ver y el pensar la complejidad de interacciones que territorios y paisajes pueden revelar, pues es donde son legitimadas o rechazadas las teorías. El trabajo de campo es comienzo, medio, fin y reinicio de la investigación geográfica; es el laboratorio de los geógrafos que evalúan (y producen) representaciones espaciales, que proponen teorías.

El trabajo de campo (por la didáctica e investigación) revela la singularidad geográfica, que tiene como síntesis las dialécticas: revisión de conceptos espaciales $\leftrightarrow$ análisis de datos espaciales; interpretación de representaciones mentales del espacio $\leftrightarrow$ formulación de esquemas interpretativos del espacio; explicación de la situación espacial $\leftrightarrow$ abordaje general o totalizante del espacio. J. Tricart muestra, con el enfoque sistémico, la inseparabilidad entre teoría y observación, en la dialéctica análisis-síntesis, entendiendo que todo sistema es abierto; considera la capacidad del geógrafo de revelar el objeto en las representaciones espaciales -en cartas, en entrevistas, en narrativas, en la confrontación de teorías y hechos, para el desarrollo disciplinar. También Archela y Théry (2008) defienden la necesidad de aprehender lo visible y lo invisible de las representaciones espaciales, como concepciones ideológicas de la sociedad.

La preocupación filosófica con lo empírico y su status científico (que lleva a K. Popper a pensar el racionalismo crítico) hace creer que el trabajo de campo es la fuente que vivifica la singularidad geográfica: una ciencia humana reveladora de los múltiples procesos que forjan la interacción sociedad-naturaleza y que, a la luz de los métodos filosóficos, comprende las existencias geográficas subsidiadas por el espacio. Racionalizar el espacio geográfico, críticamente, es práctica singular de la disciplina posible a través del trabajo de campo, pues a través del territorio y del paisaje se traslapa economía, política y representación del mundo, objetivación materialista y subjetivación fenomenológica, la existencia espacial. Si la totalidad es el conjunto de las relaciones esenciales de un fenómeno (Silva, 2000), el trabajo de campo posibilita encontrar, en su complejo, la interacción entre el ser del espacio (mediado por los conceptos disciplinares) y el propio fenómeno.

Dudar y buscar la verdad relativa a las producciones espaciales (desde la dialéctica) o a sus representaciones (desde la fenomenología) son acciones que motivan la aventura, solitaria o compartida, del geógrafo en el trabajo de campo, lo cual fundamenta las singularidades disciplinares a través de la racionalización crítica del espacio. Se justifica que la fenomenología permite construir un discurso sobre el espacio como producto social, sin olvidar sus categorías básicas:

5 Ver en M. Heidegger la relación hecha entre Filosofía y Ciencia, con sus crisis. 
percepción, esencia y existencia; y el marxismo explica el acto del trabajo humano como productor también de la conciencia en el/del mundo (Scarlato; Costa, 2017).

Tales preceptos están en la base de nuestras experiencias académicas de trabajos de campo en las carreras de Geografía de la Universidad de Brasilia y de la Universidad de San Paulo, asumiendo el análisis empírico como un momento del método y también de la didáctica en Geografía (éstas son dos de las más importantes universidades nacionales y destacados centros de producción del conocimiento geográfico brasileño).

Las problemáticas de campo presentadas emergen más de la preocupación por la enseñanza teórica y de método a los estudiantes, y menos de las ataduras curriculares de éstas instituciones o de la inmediatez de la colecta de datos empíricos (procedimiento instrumental metodológico y no propiamente método, confusión que este artículo denuncia).

\section{Experiencia de trabajos de campo en la UnB: cuestiones de método y didáctica}

La UnB, en la capital federal, es el principal centro académico del interior brasileño, donde la licenciatura en Geografía, fundada al mismo tiempo que la nueva ciudad, en la década de 1960, siempre cuestionó las contradicciones del ordenamiento territorial y de la integración regional, nacional y latinoamericana. Una carrera inaugurada en el contexto del Brasil desarrollista, de la industria automovilística, del equipamiento del territorio con infraestructuras productivas propias (e inversión extranjera), que deberían sustentar el mercado interno con una política de sustitución de las importaciones. Esa Geografía surge en una ciudad construida para que:

[... el Norte, el Nordeste y el Centro-Oeste fueran incorporados a la frontera macroeconómica brasileña, en beneficio de la calidad de vida de la nueva clase media del Sudeste y del Sur [...]. Poblaciones tradicionales, nuevos esclavos de la construcción, del campo y del capital financiero, en Brasilia, Goiânia, Cuiabá, Campo Grande, Belém, Manaos, Recife, Salvador [... y y muchas otras ciudades de las tres regiones incorporadas al mercado sudestino, son singularidades efectivas del drama que antecede y resulta en el y del poder desarrollista populista del último siglo (Costa; Steinke, 2014, p. 26).

Estas variables espaciales multiescalares nos hacen creer que toda asignatura (teórica o aplicada), en Geografía, puede incorporar, didácticamente, trabajos de campo, para estimular al futuro profesor o investigador a la observación e interpretación rigurosas de los procesos catalizadores de la interacción sociedad-naturaleza. Para Claval (2013), la práctica de campo no consiste en observar lo que acontece en los lugares, sino en transformar, con el análisis, la visión puntual de los fenómenos o articular esos lugares. Lo que exige asimilar las dimensiones productiva (dialéctica) y emocional (fenomenológica) del espacio.

En la UnB, las asignaturas que ofertamos abordan la formación y la dinámica territorial urbano-rural, en las escalas local, nacional y latino-americana integradas en tres planos: clases teóricas (en la UnB), clases de campo (en el Distrito Federal-DF) y trabajos de campo (en San Paulo, Belo Horizonte o ciudades coloniales mineras). Urbanización, metropolización, 
industrialización y patrimonialización son macro-temas desarrollados tanto en las asignaturas como en la investigación (Costa, 2011; Costa; Steinke, 2014;Costa; Peluso, 2016). Asumir la complejidad de las temáticas y detallarlas en campo, con procedimientos, corrobora a Silva (1988), al decir que no podemos confundir investigación científica con el trabajo mecánico de colectar datos en laboratorio, en campo o en gabinete; ello requiere, además, reconstrucción histórica del fenómeno o conexiones de hechos y eventos en escalas.

Las clases de campo (en el DF) y los trabajos de campo (en el Sudeste brasileño) buscan: (i) compartir el conocimiento de las aulas con grupos sociales e instituciones, (ii) estimular la enseñanza-aprendizaje vía argumentos críticos-propositivos, con base empírica conocida o no por los estudiantes, (iii) realizar acciones concretas (devolutiva), por medio del conocimiento producido en las materias, junto con las comunidades, articulando enseñanza-investigación-extensión, (iv) demostrar la importancia de la relación teoría-empiría, para revisión, desmitificación y potencialización de los conceptos geográficos, enseñando una Geografía más activa y menos tediosa, y (v) propiciar en el alumno una formación ciudadana y humanística, para un pensamiento y prácticas dirigidas a cambios espaciales demandados por el mundo del presente. P. Claval ve el estatus científico del campo en la comunión de lugares, en la vanidad del joven investigador y su avidez por el nuevo conocimiento; de forma que su experiencia empírica puede dar origen a un análisis casi psicoanalítico o etnográfico. La didáctica del campo en la Geografía aguza el autoconocimiento y caracteriza el gusto del futuro geógrafo por la investigación, operando el método (filosófico) y los procedimientos (metodología). Además, la relación de los estudiantes (hombres y mujeres) en el campo favorece la ruptura del histórico prejuicio de género no solamente en esa práctica disciplinar, sino en las ciencias en general. ${ }^{6}$

La metodología de la disciplina optativa Geografía Humana Aplicada (GHA), en la UnB, sirve de ejemplo. Los estudiantes se dividen en cuatro grupos temáticos de enseñanza-aprendizaje: (i) propuesta y elaboración de cartografía existencial para un planeamiento participativo de barrio en el DF (dimensión existencialista), (ii) segregación socio-espacial metropolitana y propuesta de valoración de los patrimonios del DF, usando medios audiovisuales (perspectiva dialéctica), (iii) activación popular de complejos culturales, espacios públicos y áreas verdes del DF (carácter fenomenológico), y (iv) análisis socio ambiental y gestión territorial en el DF: estudio de caso, propuesta metodológica e intervención (abordaje dialéctico). Esos grupos temáticos demandan esfuerzo discente para comprender la interacción de las cuestiones ambientales con los valores sociales y la Geografía como ciencia humana y conciencia del espacio (Silva, 2000), sin olvidar de los preceptos filosóficos en la ciencia.

Así se desenvuelve la asignatura: (i) presentación de los temas posibles de abordaje en el DF, (ii) cada grupo elije la temática y el sitio de investigación y extensión, entre las ciudades del DF, (iii) se sugiere bibliografía básica a cada grupo (especialmente geógrafos que particularizan el método, como Y-Fu-Tuan y Edward Soja), para desarrollar la práctica, (iv) se imparten cuatro clases teórico-metodológicas (métodos, proyecto de investigación-extensión y procedimientos de análisis -entrevistas, cuestionarios, oralidad, diario de campo, mapeo colectivo, cartografía social, cartografía existencial, fotografías etc.), (v) seis clases o salidas de campo en diferentes

6 Para el debate sobre la geografía universitaria y su feminización, ver el significativo análisis de Ginsburger (2015). 
ciudades del DF (relacionadas con bibliografía básica, observación empírica y procedimientos definidos para la investigación), (vi) estas seis clases o salidas de campo permiten: (a) la producción del material de la devolutiva a la comunidad \{documental, cartografía, plano de preservación o intervención ambiental, oficina popular de concientización guiada por los valores del lugar etc.) y (b) organización de la devolutiva de la investigación-extensión y (vii) inicio de las cuatro clases de campo para la aportación de cada grupo, a fin de que todos los estudiantes conozcan el material elaborado junto con la comunidad (Figuras 1 y 2 ).

Figura 1 - Estudiantes de la asignatura GHA-UnB en campo, en la Villa del Sosiego, Candangolandia, DF

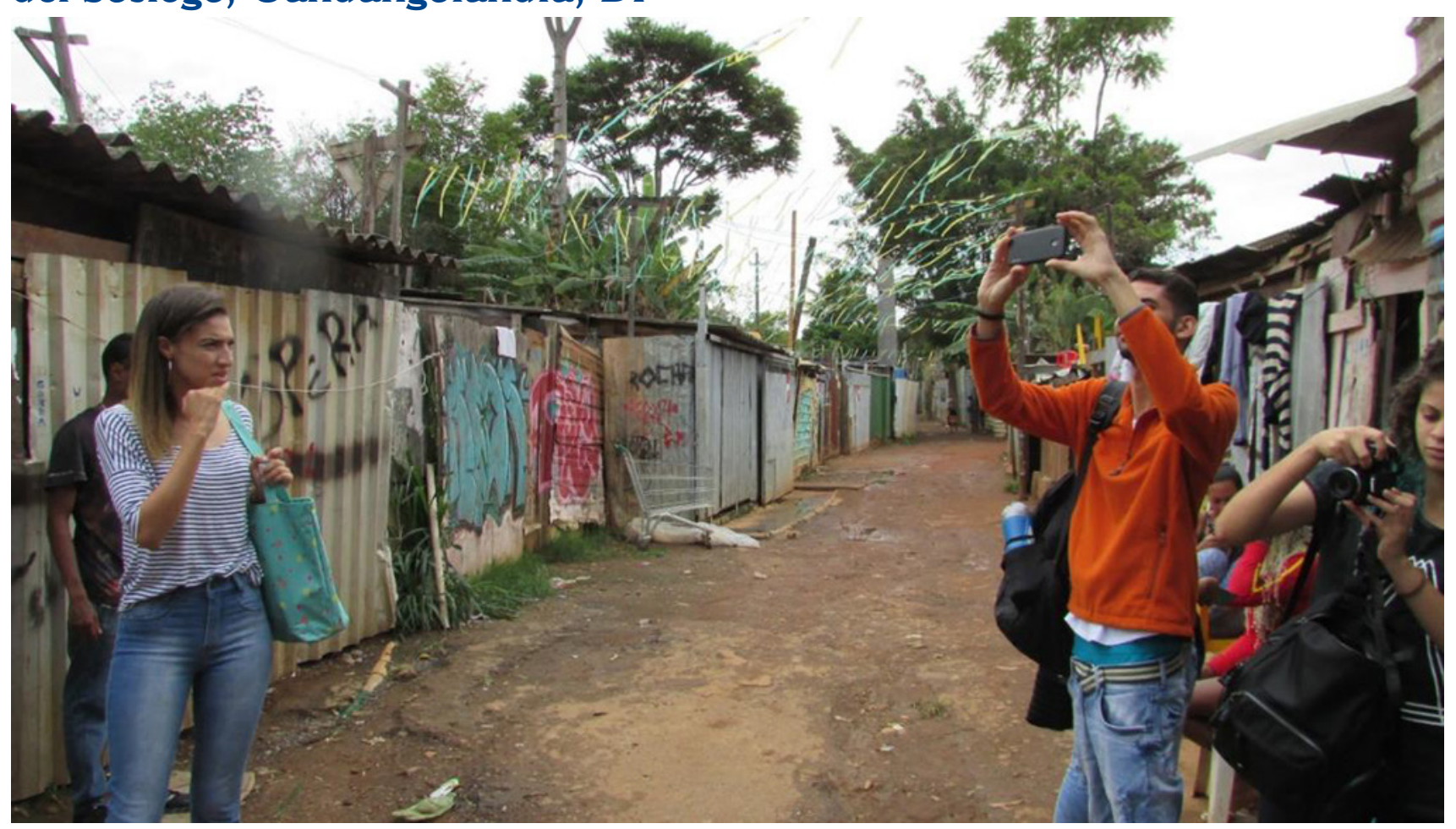

fuente: Acervo de los autores, octubre de 2018. 


\section{Figura 2 - Potencialidades y fragilidades territoriales, por la regularización de tierras y fijación popular}

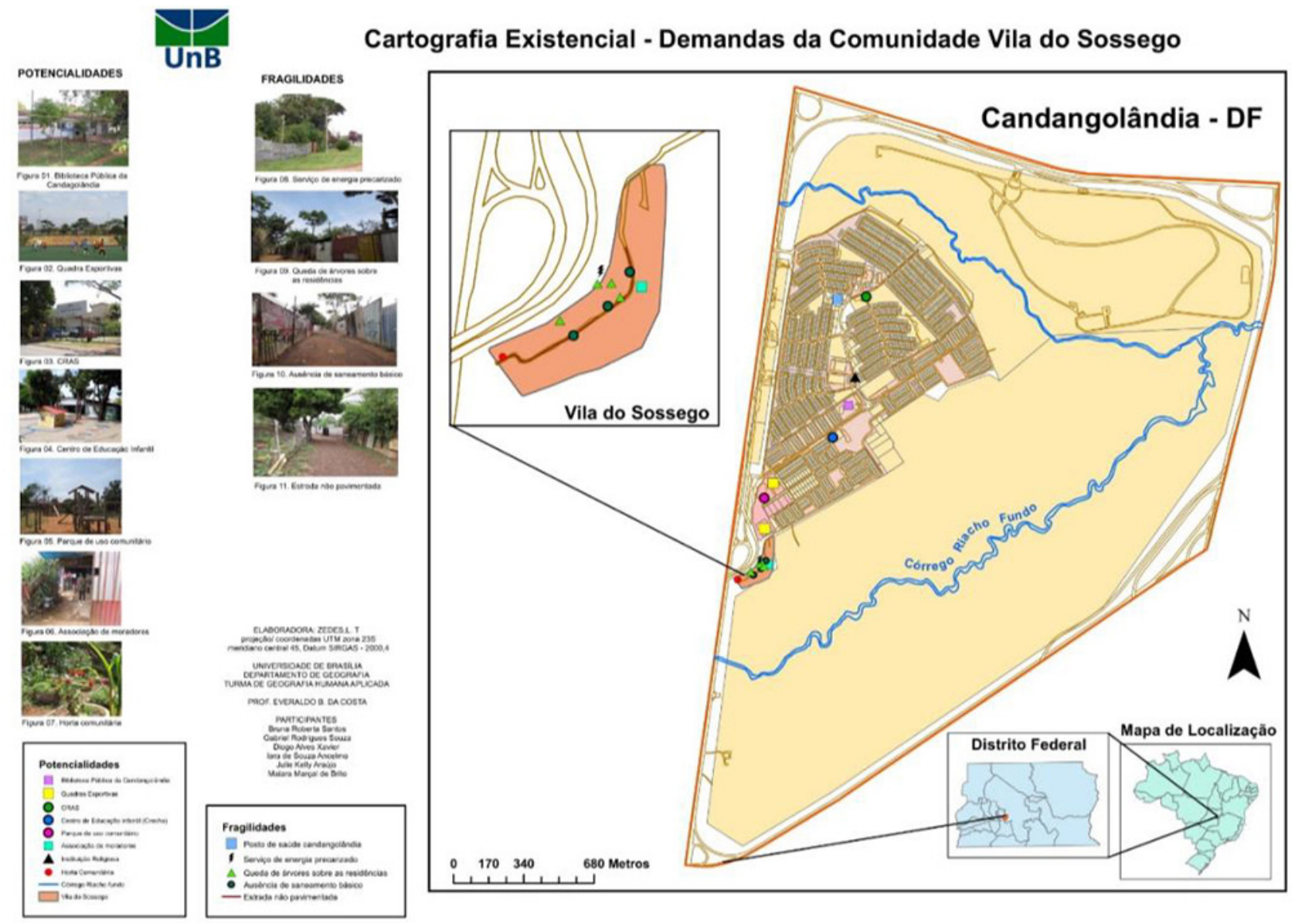

fuente: Resultado de investigación-extensión desde la asignatura de GHA (2018 - 2º semestre).

Las prácticas de campo preparan al futuro geógrafo para confrontar la realidad política espacial brasileña. Teoría, práctica, didáctica y praxis ciudadana, crítica propositiva, aproximación de los métodos, metodologías y procedimientos investigativos integran ese esfuerzo intelectual y empírico docente y discente. El objeto es cuestionado concretamente, cuando "organización del espacio, producción del espacio, formación territorial son proposiciones que visan revelar el ser geográfico, consiguiéndolo con abordajes parciales, en la dialéctica, para avanzar la empiría" (Silva, 2000, p. 21).

¿La geografía urbana brasileña seguirá padeciendo del mal acusado por A. Correa da Silva y M. de A. Abreu, hace dos décadas? Según Silva (2000), el problema mal resuelto de la crítica radical era, por un lado, rechazar la investigación empírica como momento del método, por otro, negarla como procedimiento mental, pues separar ideas y hechos no conduce a nada. De acuerdo con Abreu (2002), la geografía crítica se dirigió al énfasis de las determinaciones sociales (debate de esencia y apariencia) en un determinismo economicista que, buscando la teoría correcta, se olvidó de volver a la apariencia; olvidó el paisaje, la variabilidad de formas, las especificidades del lugar, la cultura urbana. M. A. Abreu considera la superación de esa crisis de los años 1980-1990, a partir de H. Lefebvre y C. Castoriadis, cuando la búsqueda de la esencia de los fenómenos no se haría negando el estudio de los paisajes, las formas; razón y emoción dejan 
de ser excluyentes. Para Abreu (2002), la Geografía brasileña sigue más diversificada (no menos polémica); después de décadas de empirismo y teorización apresurada del neopositivismo, los excesos del materialismo ganan nuevos ropajes. Conlleva cada vez más fuerza una Geografía cuyos procedimientos corresponden a los métodos fenomenológico y existencialista, con $E$. Husserl, M. Heidegger, M. Merleau-Ponty, J. P. Sartre etc.

Esas polémicas se enfrentan en las asignaturas que impartimos en la UnB, dada la urgencia en superar las dicotomías disciplinares y confusiones de método, en debatir las relaciones dialécticas esencia $\leftrightarrow$ apariencia, lógica formal $\leftrightarrow$ lógica concreta, razón $\leftrightarrow$ emoción, sociedad $\leftrightarrow$ naturaleza, teoría $\leftrightarrow$ empiría geográficas. Por medio del trabajo de campo, de lo empírico, el método y las singularidades geográficas son conocidas, operadas, dialectizadas y redefinidas, si asumimos la misión disciplinar en la revelación del ser del espacio, lo que exige recuperar la filosofía.

Con el trabajo de campo, con fines investigativos o didácticos, es posible enseñar a los estudiantes que la teoría (en sus matrices filosóficas de métodos) no debe tener un fin en sí misma, sino volcarse en la solución de problemas sociales en lo cotidiano. Hay que asumir los desafíos cientíícos sin abandonar los cuestionamientos filosóficos, establecer el difícil dialogo entre el conocimiento objetivo y la reflexión subjetiva.

\section{Experiencia de trabajos de campo en la USP: métodos, didáctica y formación geográfica}

El caso de la USP, localizada en la más dinámica metrópoli nacional, es notorio, por su protagonismo en la historia de la Geografía universitaria de Brasil; donde, en 1934, un grupo de estudiosos se reunió y, con el liderazgo de Pierre Deffontaines, fundó la Asociación de los Geógrafos Brasileños, pautando desde entonces una geografía de marcada influencia francesa. La Geografía de la USP, en rigor, nunca se restringió a perspectivas estrictamente empiristas; no se trata de valorar exactamente la escuela francesa, base de su formación, sino señalar esa escuela paulista como promotora del proyecto vigoroso de la Geografía Crítica en Brasil, para el combate a la dictadura militar instaurada en 1964 (Damiani, 2012).

La Geografía de la USP (la mayor difusora del conocimiento geográfico hasta la década de 1990, en Brasil, cuando se manifiesta y cataliza un nuevo panorama de esos centros en otras partes del país) debe ser contextualizada con la realidad en la cual esta inserida: la metrópoli signo de la modernidad incompleta, donde se traslapan rasgos de opulencia, debidos a la pujanza de la vida económica (epicentro nacional) y sus expresiones materiales, y señales de desfallecimiento, gracias al atraso de las estructuras sociales y políticas; todo lo más moderno puede ahí ser encontrado, al lado de las carencias más notables (Santos, 2009).

Ese contexto paulistano totalizado en el Brasil nos ha estimulado, entre 1980 y 2009, a realizar numerosos trabajos de campo, en la Geografía de la USP. Por eso, el análisis siguiente se funda en la experiencia consolidada en la asignatura Geografia Regional Sudeste. El a priori asumido, en la didáctica de esas prácticas, es el de que hay una relación directa entre el campo y la formación del ciudadano. Para Claval (2013), esa actividad no sirve solo a la mente, sino a la formación cívica o civil. La observación del terreno es lo que siempre favoreció, en Geografía, el desarrollo de sus postulados y teorías. 
Los trabajos de campo ocurrieron, a lo largo de tres décadas, en ciudades de San Paulo, Río de Janeiro y Minas Gerais, y más recurrentemente en ciudades coloniales mineras, para facilitar, empíricamente, evidenciar la interacción sociedad-naturaleza y la dialéctica espacio-tiempo, con fundamento en la fenomenología y la dialéctica. Ciudades que constituyen palimpsestos de acciones y de objetos técnicos acumulados desde el siglo XVIII; mantienen un patrimonio urbano que corresponde a la propia ciudad como el gran producto cultural de la humanidad; monumento resignificado en su totalidad urbana, por la economía espacial de la cultura. Sistemas viales antiguos y nuevos, monumentos y bienes modernos, conjunto urbanístico y barrios recientes conforman un libro de piedras que permite leer el proceso de ordenamiento del territorio con los sentidos (Scarlato; Costa, 2013).

En trabajos de campo en Ouro Preto, se estimulaba la reflexión sobre la interacción sociedad-naturaleza, con énfasis en la perspectiva espacial y emocional del barroco - arte totalizadora de la historia y del urbanismo -, donde la orografía en sí se hace barroca gracias al drama impuesto por la naturaleza. Tratar la interacción sociedad-naturaleza dentro del aula y sin la percepción del paisaje es menos productivo; las representaciones del espacio en imagen no permiten alcanzar la esencia de los paisajes; la más alta emoción se alcanza en lo empírico, que impacta al sujeto dotado de territorialidad, de historia y de capacidad aprehensiva de la singularidad geográfica. Según P. Claval, la ciencia del campo, desde su juventud francesa, estimuló el aprendizaje al aire libre, buscando las características del espacio a través del paisaje.

Los trabajos de campo permitían asimilar el significado de la orografía barroca. Ouro Preto presenta un teatro de paisaje cuyo relieve sinuoso y la plástica del arte sacro evidenciada en el frontispicio de los monumentos se adaptan al urbanismo barroco singularizado por el carácter político histórico de la interacción sociedad-naturaleza (Figura 3). La anciana del barroco - por el origen y diversidad de los efectos decorativos y de las soluciones arquitectónicas adoptadas frente a la austera naturaleza - era presentada a través del estudio empírico del paisaje y de la evaluación del ordenamiento territorial, sin olvidar los conflictos sociales representados. Esa descripción es fragmento de una clase teórica, que no sería calificada sin la experiencia o vivencia en el campo. La empiría en esas ciudades estimulaba aquello que M. Quaini (1993) sugería: romper con cierta Geografía enfeudada, que desprecia la cultura y la historia de la cultura. También favorecía enseñar a los estudiantes aplicar o rever la teoría en lo empírico, y además, desmitificar los métodos dialéctico y fenomenológico operando los conceptos. 


\section{Figura 3 - Paisaje de Ouro Preto, Brasil}

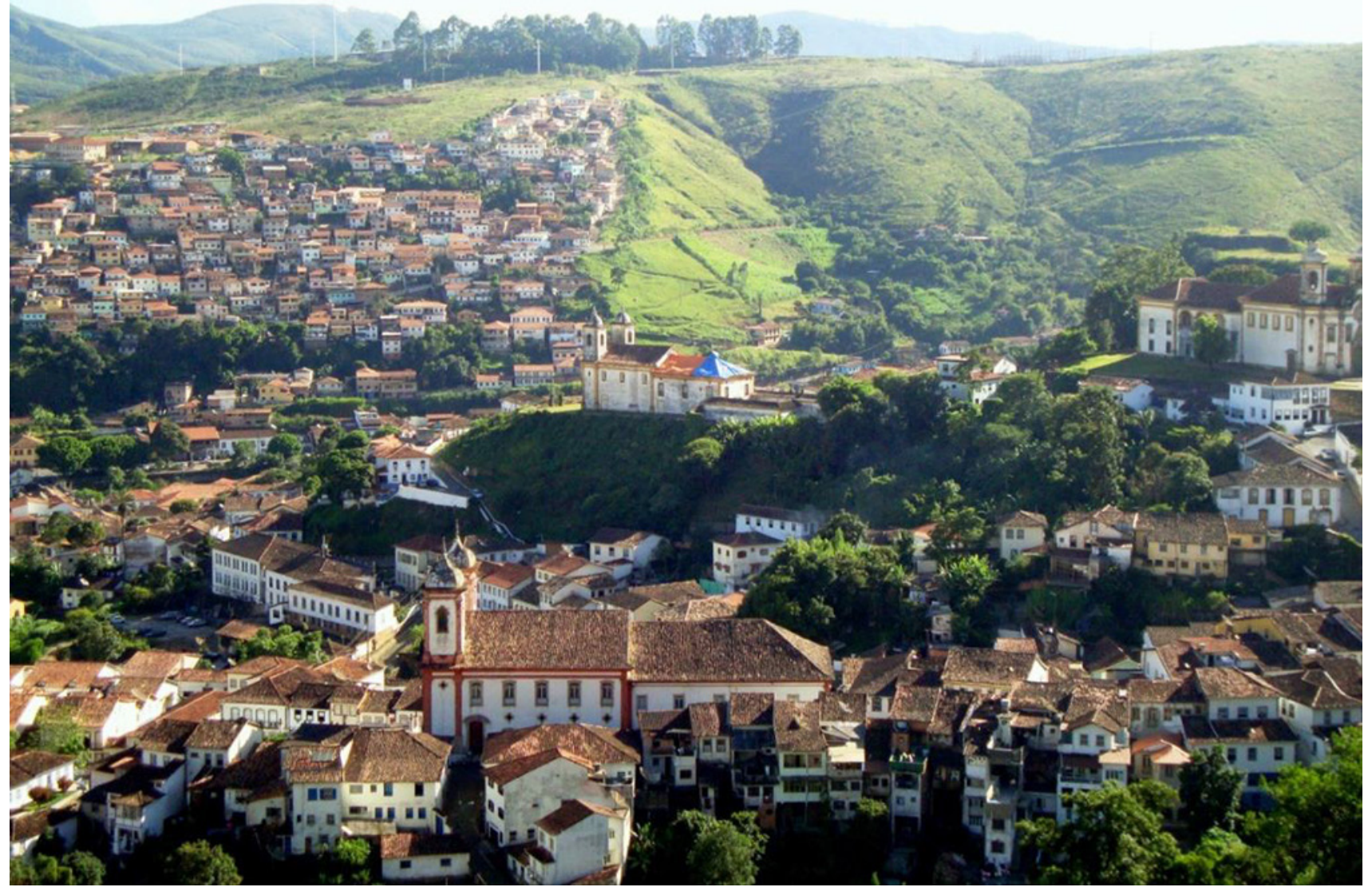

fuente: Acervo de los autores, trabajo de campo, mayo de 2009.

Los trabajos de campo nunca eran dirigidos a una única ciudad. La ruta incluía Ouro Preto y Tiradentes, en ocasiones, São João del-Rei. Hiperbólicamente, decíamos que Ouro Preto equivaldría a una "metrópoli"; Tiradentes, a una pequeña ciudad de su "región metropolitana". En clase, eso sonaba incoherente, considerando los elementos que definen la metrópoli moderna, que para nada aparecen en las dichas ciudades. El objetivo de la hipérbole era duplo; primero, romper, con la experiencia empírica, la visión metropocéntrica de los estudiantes de San Paulo; segundo, provocar la lectura de lo urbano en otra escala, cotidiano, intensidad, volumen y espíritu de la ciudad. En campo, recorriendo cada ciudad, la comparación se efectuaba en la transcendencia necesaria del espacio-tiempo urbano colonial.

En Ouro Preto, la empiría revelaba, en el interior de las manzanas, calles donde se alinean caserones de dos o tres pisos, todos adosados, y crean un volumen urbano que transciende la escala humana. Propio de la concepción urbanística barroca, no hay vacíos al interior de las manzanas. Se forma una masa construida compacta, donde el espacio urbano se impone sobre el ocupante (Figura 3). En Tiradentes, manzanas y calles forman un tablero de ajedrez, con un relieve más plano y un caserío térreo alineado y adosado, lo que permitía a los estudiantes vivenciar y comparar escalas del estar y sentir citadino (Figura 4). Esa percepción, que instiga el imaginario, ocurre en campo. El ejercicio comparativo, hecho en la didáctica clase-campo, preparaba al alumno para descubrir el objeto en sus representaciones (procedimiento propio tanto de la dialéctica cuanto de la fenomenología), y estimulaba a reconocer el papel de puntos de vistas incongruentes e incompletos, según los moldes de las enseñanzas de J. Tricart. 


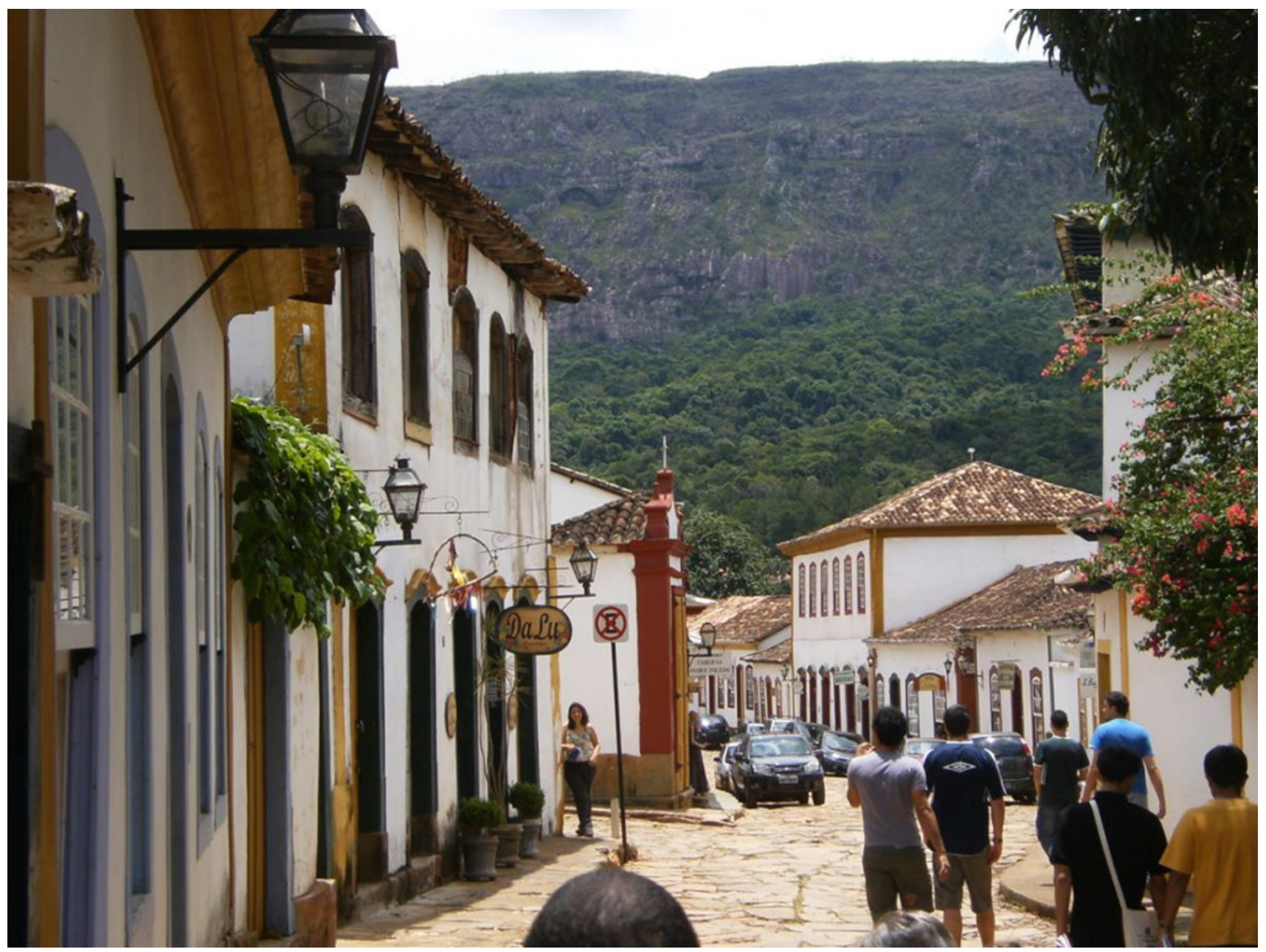

fuente: Acervo de los autores, mayo de 2009.

La lectura del paisaje, en ambas ciudades, mostraba a los estudiantes una Ouro Preto de laderas periféricas densamente ocupadas, en torno de un área declarada Patrimonio Mundial. La percepción de la totalidad territorial urbana, del paisaje y de lo cotidiano, desde el interior de su espacio barroco, denota un proceso invasivo cuyo imaginario transporta a la ciudad industrial. ${ }^{7}$ La interacción sociedad-naturaleza se entiende en la simultaneidad de objetos y de acciones de las diferentes técnicas oriundas de tres siglos de materia e imaginario urbanos revelados en la ciudad actual. En Tiradentes, emparedada por la preservada sierra de San José (Figura 4), se opera, más fácilmente, la reconstrucción imaginaria del espacio setecentista. La ruptura técnica (y conflicto) de los momentos de producción urbana es causada por el automóvil, que impacta el paisaje, desmonta la escala humana y tonifica la percepción; una extravagancia con los paisajes de esos sitios.

La relación analítica de las dos ciudades permitía trabajar con la fenomenología y la dialéctica relativas a la interacción sociedad-naturaleza. Temas como (i) espacio urbano del período pre-industrial brasileño, (ii) sensibilidades y significados de ciudades en escala humana, (iii) producción y percepción del paisaje, (iv) imaginario y espacio, (v) procesos de regionalización en Brasil y (vi) planeamiento en variadas escalas urbanas se realizaban en las actividades, en diálogo

7 Costa (2011) propone una metodología de análisis para la totalidad urbana en ciudades coloniales brasileñas. 
con los métodos fenomenológico (M. Merleau-Ponty), existencialista (J. P. Sartre) y dialéctico (G. Lukács). Se observa la ciudad como valor de uso, construida como lugar de vivienda, más allá de su significado económico para el turismo. Esos trabajos de campo eran motivados por el deseo, por la curiosidad y por la emoción, por más que P. Claval considere el deseo como la motivación central de los nuevos geógrafos en el campo. La empiría genera la experiencia corporal, o estar en el lugar para encontrar el mundo, reconocer en el otro las dificultades de la vida espacial, de la existencia localizada, de realizarse en un territorio.

En campo, el espacio imaginario se mezcla con el vivido y el percibido, dando contenido al territorio, a la conciencia y a la dinámica del presente. Esos locales nos aproximan a la naturaleza de lo urbano, pues el esfuerzo de digresiones, en el diálogo entre la ciudad y lo urbano, indica que tal naturaleza antecede la industrialización moderna (Scarlato; Costa, 2017).

El éxito de los trabajos de campo en ciudades coloniales mineras residía en la anticipación, en clase, de una geografía fundamentada en los métodos fenomenológico y dialéctico, invocando las experiencias que serian vividas empíricamente y respectando el primado de la singularidad geográfica revisada en lo empírico. Entendíamos que la sociedad, al producir sus espacios, también genera sus representaciones simbólicas manifiestas en la morfología urbana y en los elementos decorativos de viviendas, templos, instituciones y memoria (vía transposición didáctica de la Historia y Arquitectura). Para Quaini (1993), ninguna ciencia pertenece solamente a sí misma, pues su devenir es, a cada momento, solidario con el devenir general del saber y la reciprocidad de valores.

En las investigaciones docentes y en la didáctica del trabajo de campo, el esfuerzo está en captar el saber subjetivo y objetivo depositado en los lugares en forma de valor y trabajo, pues este determina el poder sobre la naturaleza y el nivel de desigualdad espacial-resultado intencional de ese poder. Según H. Lefebvre, en cierto grado de desarrollo y de poder sobre la naturaleza, la sociedad emergió sobre ella, sin desvincularse; la civilización se pretendió, simultáneamente, menos natural y más humana y los instrumentos del conocimiento lograron un grado superior de objetividad.

El trabajo de campo y el tipo de empiría a practicarse, para rever la singularidad de la Geografía, deben evaluar el espacio en un doble aspecto: cuantitativo (impactos del poder o de los progresos técnicos, cuyas intencionalidades sobre la naturaleza socializada y la naturaleza humana confieren la morfología de los paisajes y la configuración de los territorios) y cualitativo (vía el establecimiento de culturas y economías en situaciones espaciales duraderas y diversas).

En síntesis, el trabajo de campo pensado y vivido (Figura 5), en la Geografía, no debe ser transformado en un paseo recreativo; comienza en el aula y termina en ella, estimulando el gusto estudiantil por la investigación y por la docencia de una carrera aprendida y aprehendida desde el mundo y lo empírico; donde, para no ser atrapado por el instrumentalismo, hay que potencializar el método científico invitando a la filosofía o uniendo dos polos: observación y experiencia (científica) y reflexión y especulación (filosófica). El empirismo falla cuando niega la necesidad de superar lo sensible; el racionalismo falla al situar las ideas fuera de lo real que ellas conocen. 
Figura 5 - Alumnos de Geografía Regional Sudeste (USP), en trabajo de campo. Tiradentes. Coordinación de los profesores Francisco Capuano Scarlato (centro), Ailton Luchiari (arriba y a laizquierda, in memorian) y Everaldo Batista da Costa (arriba y al centro)

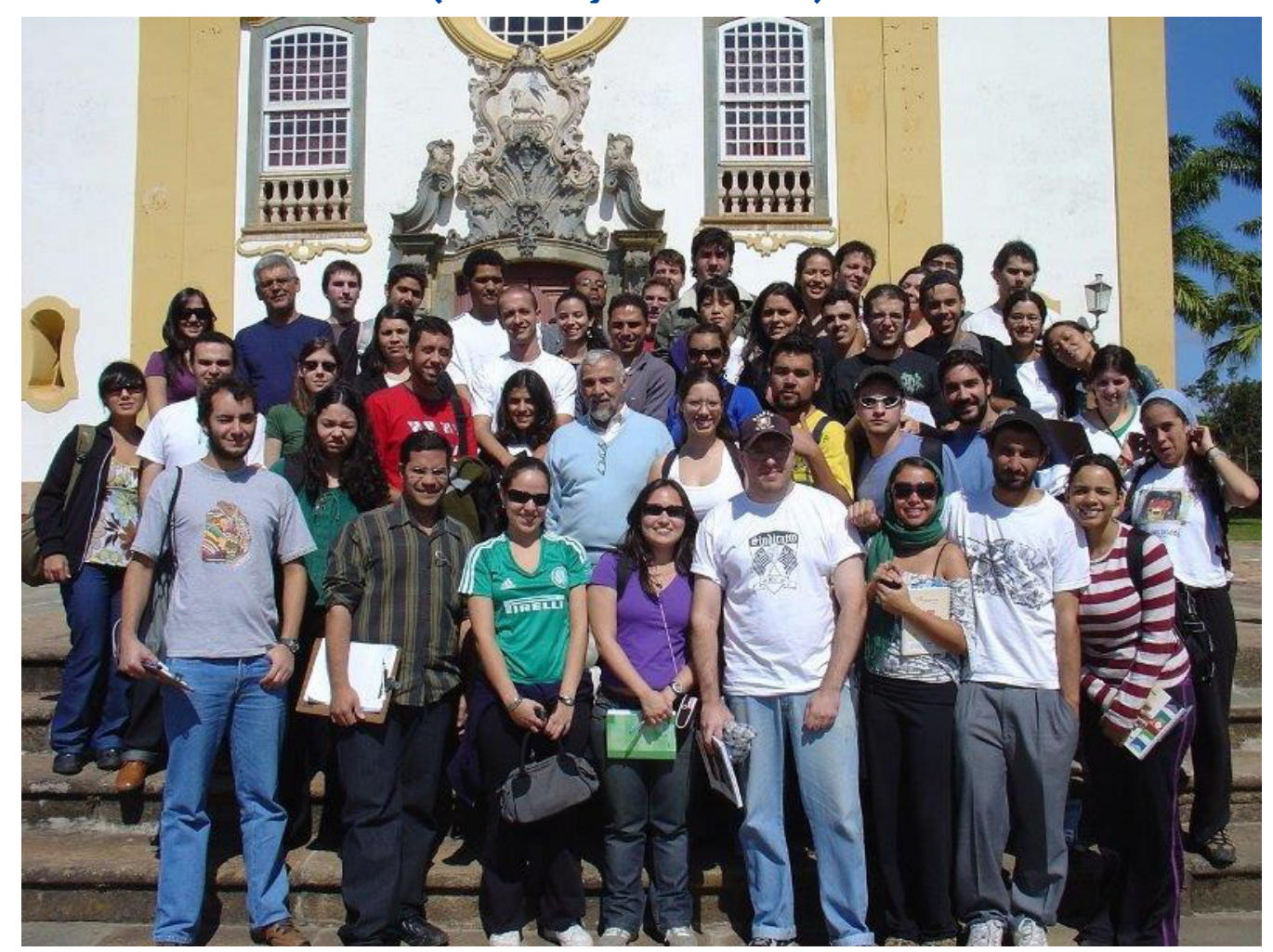

fuente: Acervo de los autores, mayo de 2009

\section{Palabras finales}

Este artículo indica el fundamental compromiso con el método, en la narrativa teórica o en la práctica de campo, sin reducirlo al instrumentalismo, a las dimensiones de metodología o de los procedimientos analíticos. El método, desde la filosofía y en la Geografía, abre camino a la verdad contenida en el objeto. Ese principio del método es condición para pensar y operar el espacio geográfico como resultado de la interacción sociedad-naturaleza.

B. Kayser dice que no hay recetas metodológicas y la metodología se afina en el trabajo de campo, por aguzar la imaginación, la astucia, las técnicas etc. Por otro lado, cualquier situación espacial debe estudiarse sobre una sólida base teórico-conceptual y un convicto compromiso político social, lo que demanda conocimiento del método, para captar el movimiento del objeto mimetizado en lo empírico. Silva (1988) afirmaba que, en Geografía, hipótesis y observación no se realizan separadamente, se estimulan recíprocamente.

Las relaciones sociales constituyentes y totalizadoras del espacio geográfico son sustentadas por intencionalidades geopolíticas escalares; comprender ese significado requiere ultrapasar la observación y la constatación del viejo positivismo, pues no se trata, restrictamente, de geometrías, sino de singularidades y universalidades conformadoras de espacialidades. La empiría 
debe captar la vida en movimiento, consolidar la formación ciudadana y estimular a reflexión filosófica, para saber actuar el y en el espacio.

Asumir la Geografía como ciencia humana crítica de las representaciones espaciales de las contradicciones requiere el compromiso con el método, así como encuadrar los procedimientos y los instrumentos analíticos en el ámbito de la producción de imágenes y de datos que, en sí y de inmediato, no contienen y no revelan el ser del espacio, sino que estructuran el raciocinio geográfico. La omisión del referido abordaje metódico propicia la confusión sobre lo que es la Geografía y su función en el mundo del presente, y aquilata las más polémicas dicotomías disciplinares espacio || tiempo, espacio || sociedad, sociedad || naturaleza, geografía física \| geografía humana.

Los métodos filosóficos favorecen entender la existencia geográfica subsidiada por el espacio. Por ejemplo, si quisiéramos tratar la Geografía como ciencia adecuada a los estudios ambientales, no podemos despreciar su unidad metodológica fundada en el espacio geográfico, categoría significante de una totalidad dialéctica que no pierde de vista las bases de la existencia de la sociedad y del individuo. La realidad espacial ocurre como una totalidad de complejos que son en si mismos, relativamente, también totalidades; la dialéctica objetiva del espacio es operada cuando se comprende la génesis real, la autoexplicitación, la interacción y la síntesis de dichos complejos, sin olvidar el lugar especial de las emociones y de los imaginarios para atribuirles sentido - así se opera el diálogo y se supera el embate entre el materialismo dialéctico (Lukács, 2012) y la fenomenología existencialista (Sartre, 2002).

Cabe enfatizar que el trabajo de campo (en la didáctica e investigación) revela la singularidad geográfica, que tiene por síntesis las dialécticas: revisión de conceptos espaciales $\leftrightarrow$ análisis de datos espaciales; interpretación de representaciones mentales del espacio $\leftrightarrow$ formulación de esquemas explicativos del espacio; explicación de la situación espacial $\leftrightarrow$ abordaje general o totalizante del espacio.

Hay que refinar, con los procedimientos y, notoriamente, con los métodos, el tipo de empiría a practicarse en Geografía. La experiencia de clases e investigaciones desde la UnB y la USP confirma que la Geografía fundamentada en los métodos y preocupada, filosóficamente, con la empiría y con las técnicas (huyendo del instrumentalismo) sitúa el trabajo de campo como la fuente que vivifica la singularidad de esta ciencia humana. La Geografía, en su conjunto, revela múltiples procesos que fuerzan la interacción sociedad-naturaleza y opera la racionalización crítica del espacio geográfico como su modus operandi, acercando reflexión subjetiva y conocimiento objetivo.

\section{Referencias}

ABREU, M. A cidade da geografia no Brasil. In: OLIVEIRA, L. (Ed.). Cidade: história e desafios. Rio de Janeiro: FGV, 2002. p. 42-59.

ARCHELA, R.; THÉRY, H. Orientation méthodologique pour la construction et la lecture de cartes thématiques. Confins, Paris, n. 3, p. 1-18, 2008. doi: 10.4000/confins.3483.

BLACKBURN, S. Dicionário Oxford de Filosofia. Rio de Janeiro: Jorge Zahar, 1997.

BUNGE, M. Buscar la Filosofía en las Ciencias Sociales. México: Siglo XXI, 2013. 
CLAVAL, P. Le rôle du terrain en géographie: des épistémologies de la curiosité à celles du désir. Confins, Paris, n. 17, p. 1-17, 2013. doi: 10.4000/confins.8373.

COSTA, E. Utopismos patrimoniais pela América Latina: resistências à colonialidade do poder. In: COLÓQUIO INTERNACIONAL DE GEOCRÍTICA, 1., 2016, Barcelona. Actas... Barcelona, 2016. p. 1-32.

COSTA, E. Totalidade urbana e totalidade mundo: as cidades coloniais barrocas face à patrimonialização global. Tese (Doutorado em Geografia) - Faculdade de Filosofia, Letras e Ciências Humanas, Universidade de São Paulo, São Paulo, 2011.

COSTA, E.; PELUSO, M. Imaginário urbano e situação territorial vulnerável na Capital do Brasil. Biblio 3W - Revista Bibliográfica de Geografía y Ciencias Sociales, Barcelona, v. 21, n. 1151, p. 1-36, 2016. url: http://www.ub.es/geocrit/b3w-1151.pdf.

COSTA, E.; STEINKE, V. Brasília meta-síntese do poder no controle e articulação do território nacional. Scripta Nova, Barcelona, v. 18, n. 493, p. 1-3, 2014. url: http://revistes. ub.edu/index.php/ScriptaNova/article/view/15033.

DAMIANI, A. Elementos da obra de Henri Lefebvre e a Geografia. Revista do Departamento de Geografia, São Paulo: USP, p. 254-283, 2012. Volume Especial. url: https://doi.org/10.7154/RDG.2012.0112.0013.

GINSBURGER, N. Les premières géographes universitaires en France: enquête sur les débuts d'une féminisation disciplinaire (1913-1928). Cybergeo - European Journal of Geography, n. 734, 2015. url: http://journals.openedition.org/cybergeo/27138.

HEIDEGGER, M. Introdução à filosofia. São Paulo: Martins Fontes, 2009.

HORKHEIMER, M. O eclipse da razão. São Paulo: Antígona, 2015[1947].

HUSSERL, E. La fenomenología y los fundamentos de la ciencia. México: Unam, 2014. KAYSER, B. O geógrafo e a pesquisa de campo. Boletim Paulista de Geografia, n. 84, p. 92-106, 2006. url: https://www.agb.org.br/publicacoes/index.php/boletim-paulista/ issue/view/57.

KOSIK, K. Dialética do concreto. Rio de Janeiro: Paz e Terra, 1976.

LACOSTE, Y. A pesquisa e o trabalho de campo: um problema político para os pesquisadores, estudantes e cidadãos. Boletim Paulista de Geografia, n. 84, p. 71-96, 2006. url: https://www.agb.org.br/publicacoes/index.php/boletim-paulista/article/view/729.

LACOSTE-DUJARDIN, C. A relação de pesquisa. Herodete, n. 8, p. 3-22, 1977.

LEFEBVRE, H. Lógica formal, lógica dialética. Rio de Janeiro: Civilização Brasileira, 1975.

LUCHIARI, A. Tratamento da informação geográfica: estudo sobre a distribuição espacial de categorias socioprofissionais. Tese (Livre-docência em Geografia) - Faculdade de Filosofia, Letras e Ciências Humanas, Universidade de São Paulo, São Paulo, 2013.

LUKÁCS, G. Para uma ontologia do ser social. São Paulo: Boitempo, 2012. v. 1. 
MATTHEY, L. Éthique, politique et esthétique du terrain: cinq figures de l'entretien compréhensif. Cybergeo - European Journal of Geography, n. 312, 2005. url: http://journals.openedition.org/cybergeo/3426.

MERLEAU-PONTY, M. Fenomenologia da percepção. São Paulo: Martins Fontes, 2006. MORAES, A. Geografia, interdisciplinaridade e metodologia. Geousp - Espaço e Tempo, v. 18, n. 1, p. 9-39, 2014. url: www.revistas.usp.br/geousp/article/view/81075.

MORAES, A. Na trilha do purgatório: política e modernidade na geografia brasileira contemporânea. In: SILVA, J.; LIMA, L.; DANTAS, E. (Ed.). Panorama da Geografia Brasileira. São Paulo: Annablume, 2006. v. 2. p. 39-46.

POPPER, K. Textos escolhidos. Rio de Janeiro: Contraponto, 2010[1960].

QUAINI, M. A construção da geografia humana. Rio de Janeiro: Paz e Terra, 1993.

ROBIC, M.-C. Approches actuelles de l'histoire de la géographie en France: au-delà du provincialisme, construire des géographies plurielles. Inforgeo, p. 53-76, 2006. url: https://halshs.archives-ouvertes.fr/halshs-00734114/document.

SANTOS, M. Metrópole corporativa fragmentada. São Paulo: Edusp, 2009.

SANTOS, M. A natureza do espaço. São Paulo: Edusp, 2002.

SARTRE, J. Crítica da razão dialética. Rio de Janeiro: DPEA, 2002.

SCARLATO, F; COSTA, E. La nature de l'urbain. Confins, Paris, n. 30, p. 1-22, 2017. url: https://journals.openedition.org/confins/11676.

SCARLATO, F; COSTA, E. Geografia e patrimônio urbano: questão metodológica. Espaço e Geografia, Brasilia: UnB, v. 16, n. 2, p. 1-18, 2013. url: http://lsie.unb.br/ espacoegeografia/index.php/espacoegeografia/issue/view/22.

SILVA, A. A aparência, o ser e a forma. Geografia e método. Geographia, n. 3, p. 7-25, 2000. url: http://periodicos.uff.br/geographia/article/view/13372.

SILVA, A. O espaço fora do lugar. São Paulo: Hucitec, 1988.

SOUZA, M. Meio ambiente e desenvolvimento sustentável. As metáforas do capitalismo, Cronos, Natal, v. 10, n. 2, p. 101-117, 2009. url: https://periodicos.ufrn.br/cronos/ article/view/3289.

THÉRY, H.; MELLO-THÉRY, N.; GIRARDI, E.; HATO, J. Géographies du travail esclave au Brésil. Cybergeo - European Journal of Geography, n. 541, 2011. url: http:// journals.openedition.org/cybergeo/23818.

TRICART, J. O campo na dialética da geografia. Geousp - Espaço e Tempo, v. 21, n. 1, p. 305-314, 2017. url: http://www.revistas.usp.br/geousp/article/view/125762. 